REZENDE, Irene Nogueira de. Literatura, história e farmácia: um diálogo possível. História, Ciências, Saúde - Manguinhos, Rio de Janeiro, v.22, n.3, jul.-set. 2015, p.813-828.

Resumo

\section{Literatura, história e farmácia: um diálogo possível}

\section{Literature, history and pharmacy: a possible dialogue}

Irene Nogueira de Rezende

Pós-doutoranda, Programa de Pós-graduação de História da Ciência/Universidade Federal de Minas Gerais. Av. Antonio Carlos, 6.627

31270-901 - Belo Horizonte - MG - Brasil inrezende@uol.com.br

Recebido para publicação em março de 2013. Aprovado para publicação em dezembro de 2013.
No Centro de Memória da Faculdade de Farmácia da UFMG encontram-se documentos relativos à passagem de Carlos Drummond de Andrade pela instituição, fato que levou à reflexão sobre a presença da farmácia e do farmacêutico na literatura. Por meio de diálogo interdisciplinar e de pesquisa sobre elementos que comprovassem essa presença, sua efetiva participação e presença na literatura, buscou-se historicizar essa vinculação não só do poeta de Itabira, mas de outros homens de letras, sendo profissionais farmacêuticos ou inspirados por eles. Objetivou-se, igualmente, apontar alguns elementos que fundamentem e demonstrem a importância desse profissional na sociedade brasileira do final do século XIX e primeira metade do XX.

Palavras-chave: farmácia; literatura; história da ciência; interdisciplinaridade.

Abstract

In the Memory Center of the Pharmacy School of UFMG there are documents relating to the passage of Carlos Drummond de Andrade through the institution, a fact that has led to reflection on the presence of the pharmacy and the pharmaceutical expert in literature. By means of interdisciplinary dialogue and research into elements that prove this presence, active participation and presence in the literature, an attempt was made to historicize these ties, not only of the poet from Itabira, but other men of letters, be they pharmaceutical professionals or people inspired by them. The objective was also to highlight some evidence that supports and demonstrates the importance of this professional in Brazilian society of the late-nineteenth century and early-twentieth century.

Keywords: Pharmacy; literature; history of science; interdisciplinarity. 
Eu quisera que o jovem cronista me informasse desde quando foi declarado o repúdio entre a profissão de farmacêutico e a cultura de letras; desejara que me expusesse os motivos desconhecidos, pelos quais os dedos que enrolam pílulas estão, por esse fato, inibidos de empunhar uma pena ou tanger uma lira (Pires, 29 jun. 1901).

Por ocasião das comemorações dos 100 anos de fundação da Faculdade de Farmácia da Universidade Federal de Minas Gerais (UFMG), várias cerimônias foram realizadas e talvez a mais expressiva tenha sido a inauguração do Centro de Memória da Faculdade (CMF) de Farmácia. Projeto antigo do professor Gerson Pianetti, o CMF guarda um grande número de objetos que remete, evidentemente, ao mundo das boticas e "pharmacias", além de documentos gerados ao longo de um século de funcionamento da instituição, fundada em 1911.

Em meio ao corpo documental da Faculdade encontram-se - infelizmente poucos - papéis que testemunham a passagem do poeta Carlos Drummond de Andrade (1902-1987) como aluno da casa. Embora tenha recebido seu diploma em 1925, ele jamais exerceu a profissão.

Mas essa feliz coincidência, de se ter aquele que é considerado o maior poeta brasileiro como egresso do curso de farmácia, aponta para um tema curioso e recorrente: por que a farmácia teve convivência tão estreita com a literatura e, ainda, por que serviu de inspiração para tantos autores, seja na poesia, seja na prosa? Que artimanhas da cultura, da ciência e da memória uniram a farmácia e a literatura? Como a criatividade e a observação passeavam por frascos e fórmulas, pequenas balanças, almofarizes e drágeas e, ao fim e ao cabo, se concretizando em fontes inspiradoras para obras literárias da mais alta qualidade? E, por fim, há uma interpretação histórica que elucide e fundamente essas questões? Dito de outra forma, examinar a literatura sob esse viés seria uma forma de (re)conhecer a força simbólica da figura do farmacêutico (e do espaço físico da farmácia) que por tanto tempo estimulou a inspiração dos escritores, ocupando um lugar privilegiado na galeria de personagens que frequentavam tão assiduamente romances, contos e novelas.

Esses pressupostos conduzem, por outro lado, ao diálogo interativo da história com outras disciplinas, o que já é fato consolidado, mas não se configura num esquema dogmático finalizado e fechado para outras experiências, questionamentos e ampliação de novas abordagens. Tentar-se-á uma análise interdisciplinar entre a história das ciências e a literatura num exercício sobre a força da presença da farmácia e do farmacêutico na literatura brasileira nos séculos XIX e XX. Neste texto busca-se compreender também a imagem da prática científica vista como essencialmente racional, não se levando em consideração outras variáveis que interferem nessa atividade: os aspectos sociais e culturais vividos por aqueles que trabalharam nos vários segmentos científicos. E ainda tentar-se-á evidenciar que a articulação entre ciência e literatura é bem maior do que se poderia pensar.

Já se tornou mais que banal a expressão "crise de paradigmas" para explicar a falência de certos modelos explicativos no estudo da história. Dentro do contexto globalizante em que vivemos e do esfacelamento de verdades absolutas é imprescindível buscar novos arsenais de conceitos que se coadunem com a realidade vivida. A consciência de que, a 
cada dia, caem por terra normas e teorias tidas como incontestáveis resulta em experiências interdisciplinares na tentativa de soluções e saídas explicativas. A cada geração são colocadas novas indagações e novas maneiras de explicá-las. A esse respeito afirma Bronislaw Baczko (1985, p.309): “com efeito, todas as épocas têm as suas modalidades específicas de imaginar, reproduzir e renovar o imaginário, assim como possuem modalidades específicas de acreditar, sentir e pensar".

Assim, deve-se considerar a literatura uma legítima manifestação da cultura de determinada sociedade. E, se é uma manifestação legítima, é um registro que o historiador pode e deve explorar. Refletindo sobre a ligação entre a história e a literatura, François Hartog declarou em recente entrevista:

E me parece que o escritor, o verdadeiro escritor, se posso assim dizer, é aquele que considera o seu trabalho 'dizer' o mundo de várias maneiras. Ele pode, não havendo estas amarras que estão no domínio das ciências humanas e sociais, apreender, de modo mais rápido e imediato, as coisas que estão se passando. E, é preciso dizer, que ele pode se equivocar completamente. Todavia, ele pode também, deste modo, dar uma expressão aos fenômenos, uma expressão que eles ainda não possuem. E assim, penso, ele pode ser muito precioso para um historiador ou para homens das ciências humanas e sociais (Rodrigues, Nicolazzi, dez. 2012, p.361).

Sem nos estender muito nas considerações teórico-metodológicas, é bom assinalar que há várias décadas o estudo da ciência já vem sendo confrontado pela necessidade do diálogo com outras disciplinas para uma melhor compreensão de certos fenômenos. Do total racionalismo de que se revestiu a ciência a partir dos iluministas, hoje vivemos uma época em que essa postura excessivamente cartesiana é com frequência contestada. O médico e cientista polonês Ludwik Fleck (1896-1961), em livro de 1935, refletia sobre o racionalismo exacerbado da ciência em geral, discutindo aspectos epistemológicos e levando à compreensão de que não se podia estudar a ciência isoladamente e descolada de seu contexto histórico e social, concebendo-a como uma atividade social e coletiva. Embora não seja de leitura fácil, suas reflexões inovadoras são fundamentais para quem se dedica ao estudo da história e da teoria da ciência (Fleck, 2010).

O filósofo austríaco, naturalizado inglês, Karl Popper (1902-1994) igualmente se preocupou com a natureza da atividade científica e questões epistemológicas envolvendo o conhecimento científico sob um viés demasiadamente cartesiano. Ele observou em uma de suas palestras que "deve ser óbvio que a objetividade e a racionalidade do progresso em ciência nada têm a ver com a objetividade e a racionalidade pessoal do cientista. A grande ciência e os grandes cientistas atuam como os grandes poetas, sob a inspiração, muitas vezes, de intuições não racionais" (Popper, 1976, p.103).

Neste trabalho considera-se a interdisciplinaridade uma prática que atua na convergência das diversas áreas do saber, ou seja, a interação entre a história, a literatura e as práticas farmacêuticas. Tarefa, talvez, um pouco complicada porque "se trata de apreender o registro das nuanças das sensibilidades de uma época, o seu 'clima', o seu 'ethos', aquilo que, no passado, corresponderia ao sistema de valores, conceitos e noções que pautaria a vida dos homens e guiaria as práticas sociais" (Pesavento, 1996, p.109). 
A literatura é, pois, uma fonte para o historiador, mas privilegiada, porque lhe dará acesso especial ao imaginário, permitindo-lhe enxergar traços e pistas que outras fontes não lhe dariam. Fonte especialíssima, porque lhe dá a ver, de forma por vezes cifrada, as imagens sensíveis do mundo. A literatura é narrativa que, de modo ancestral, pelo mito, pela poesia ou pela prosa romanesca, fala do mundo de forma indireta, metafórica e alegórica. Por vezes, a coerência de sentido que o texto literário apresenta é o suporte necessário para que o olhar do historiador se oriente para outras tantas fontes e nelas consiga enxergar aquilo que ainda não viu (Pesavento, 28 jan. 2006, p.5).

\section{A importância das farmácias e a figura do farmacêutico}

A figura do farmacêutico como salvador de vidas e mitigador de dores teve um vigoroso reforço nas primeiras décadas do século XX com o aumento exponencial da comercialização de medicamentos; afinal, eram esses profissionais responsáveis pelas vendas e muitas vezes pela prescrição. Os estabelecimentos farmacêuticos serviram de cenário físico a esse tipo de comércio no qual, por outro lado, se desenvolveram práticas sociais como as relações de sociabilidade vividas e vivenciadas nas farmácias espalhadas por todo o Brasil, particularmente no final do século XIX até meados do XX, quando essas casas negociantes constituíam um lócus de grande importância dentro das comunidades urbanas. O ambiente físico de uma farmácia antiga é descrito pelo historiador das ciências Flávio Edler (2006, p.94):

No final do século XIX, as farmácias ainda mantinham boa parte do instrumental tecnológico herdado das boticas. Na sala da frente, prateleiras repletas de frascos de louça, brancos ou negros, de tamanho uniforme e inscrições douradas a fogo, onde eram guardadas as substâncias postas à venda. Nas dependências dos fundos, vedadas aos clientes, boiões, frascos de vidro e grandes potes de louça ou de barro encerravam o material sólido ou em pó. Lá também ficavam os instrumentos: almofariz para a maceração, cortador de raízes, tachos de bronze e coadores diversos; utensílios fundamentais para o preparo das receitas solicitadas pelos médicos ou muitas vezes indicadas pelos próprios farmacêuticos.

Nas últimas décadas do século XX, as farmácias vão passar por um processo de transformação de tal porte que eliminará o caráter socialmente agregador que as caracterizou durante todo esse tempo. Os antigos e grandes armários de madeiras de lei e vidros bisotados deram lugar às gôndolas contemporâneas nas quais se vende de goma de mascar até ração para cães, e os remédios foram empurrados para uma modesta parede nos fundos, afastando, assim, qualquer possibilidade de um convívio social mais estreito entre os fregueses. Edler (2006, p.99) observa que: "O desenvolvimento dos laboratórios farmacêuticos e o consequente aumento da utilização de medicamentos prontos nacionais ou importados transformaram, aos poucos, o perfil das farmácias, que, cada vez mais, foram assumindo características próprias dos estabelecimentos comerciais voltados para o varejo".

Ainda segundo Edler, as transformações no modus vivendi das farmácias não se deram de forma homogênea. Nas cidades maiores as farmácias passaram a oferecer produtos de beleza e perfumaria, aumentando consideravelmente o público consumidor feminino. Por outro lado, nas pequenas cidades do interior do país desprovidas de assistência hospitalar adequada, 
"muitas farmácias acabaram se transformando em espaços de prática médica, abrigando consultórios clínicos, onde eram oferecidas consultas à população local" (Edler, 2006, p.99).

As farmácias de hoje perderam quase todo o apelo que atraía pessoas para seus interiores, estabelecendo laços de sociabilidade e reafirmando o caráter agregador desse tipo de comércio. Afinal, em tempos de poucos médicos e dificuldade de acesso a hospitais - e muitas vezes a inexistência deles - era a farmácia uma espécie de porto seguro para as populações do interior do Brasil, e o farmacêutico, frequentemente, representava de forma digna os discípulos de Hipócrates. Sem contar o grande número de pessoas que se automedicavam e preferiam a opinião do farmacêutico à dos médicos.

Tal a força do significado de "ser farmacêutico" - e este detendo o saber das fórmulas que aliviariam as dores e salvariam vidas - que essa representação pairou sobre o imaginário de gerações de escritores, quando não eram os próprios os detentores desse saber científico. Além disso, o fato de lidar com dor, angústia, medo, iminência da morte, sentimentos tão triviais no cotidiano do profissional farmacêutico, certamente serviu de ingrediente precioso para apurar e estimular a criação literária, sentimentos que atuariam como indutores e modelos para a legitimação de personagens a concretizar nas páginas de romances, contos e poesias.

A revista O Farmacêutico Brasileiro, publicada desde meados dos anos 1920 até o final dos anos 1940, reforçava, através da propaganda financiada pela multinacional alemã dos medicamentos, a Bayer, ${ }^{1}$ o caráter íntegro, disponível e caridoso do profissional atrás do balcão. O farmacêutico era revestido, então, de uma função simbólica e representado como o homem que salvava vidas e aliviava as dores mais atrozes, quase um sacerdote, que detinha o saber das manipulações, da eficiência dos medicamentos, das fórmulas dos elixires mitigantes, bem como a ciência da exata medida da cura contida nos cadinhos e frascos.

É bom esclarecer que, por essa época, as multinacionais dos medicamentos já estavam instaladas no Brasil, e atrair a simpatia dos farmacêuticos tinha, como consequência lógica, o aumento das vendas de seus produtos. Outra variável interferia ainda na maciça propaganda das empresas: a Segunda Guerra Mundial, que colocou em lados opostos alemães (donos então da maior fatia do mercado brasileiro de medicamentos) e os norte-americanos ansiosos para abocanhar seu quinhão brasileiro e afastar as fábricas "nazistas" dos aliados (Quintaneiro, 2002). De qualquer modo, havia, então, um sistemático reforço na condição simbólica do farmacêutico como o bom amigo a quem recorrer nas aflições e doenças. É o que hoje se chama estratégia de marketing.

Já bem longe vai o tempo em que o Farmacêutico - o boticário - não passava de um homem mais ou menos hábil em manipular pílulas e xaropadas. Hoje o Farmacêutico é um profissional cuja arte está intimamente ligada à ciência médica da qual é um precioso colaborador ... E, assim, como o sacerdote dá, com sua oração, que é o remédio da alma, o bom conselho, assim também acompanhados e conselhos salutares dá o Farmacêutico o remédio do corpo (O Farmacêutico..., mar. 1935, p.5). ${ }^{2}$

O Farmacêutico é, em momentos tais, o sacerdote da providência, o amigo do seu semelhante. Nenhum interesse o guia a não ser o de servir ao próximo (O Farmacêutico..., set. 1938, p.3). 


\section{A farmácia na literatura e a literatura na farmácia}

O perfil anteriormente descrito de nenhuma maneira se enquadrava na figura do farmacêutico Sebastião Veríssimo, morador da cidade gaúcha de Cruz Alta nos primeiros anos do século XX. Proprietário da Farmácia Brasileira e pai do escritor Érico Veríssimo (19051975), Sebastião fazia de seu estabelecimento uma mistura nada ortodoxa de bar, hospital, hospedaria e farmácia de manipulações, com sua nítida preferência pelo bar.

Em suas memórias Veríssimo narra como era o dia a dia da farmácia paterna e alerta os leitores para fatos aparentemente inverossímeis que se passavam no local, prevenindo que não se trata de mitomania, mas difícil mesmo de se acreditar tamanhos os absurdos. A farmácia era local de roda de chimarrão, onde se reuniam diariamente "os vadios e aposentados" da cidade. Nos fundos funcionava um mini-hospital, no qual trabalhava um médico-cirurgião italiano que operava numa sala toscamente preparada para o fim a que se destinava. Enquanto extirpava rins e tumores, remexia tripas e suturava abdômens, o doutor cantarolava "Torna a Sorrento" ou assoviava as 14 notas do "Carnaval de Veneza". A bagunça era tanta, que um dia "um gaiato com um mórbido conceito de humor colocou na soleira da porta de nossa cozinha um rim humano deformado por um tumor, que o Dr. Merlo acabara de extirpar do corpo dum paciente" (Veríssimo, 1978, p.45). Ainda contava a Farmácia Brasileira com alguns quartos ao fundo para hospedar os parentes dos doentes mais graves. O menino Érico observava e registrava os fatos ocorridos nesse mundo de tintas surrealistas. A Farmácia Brasileira de Sebastião Veríssimo serviria de modelo para a Farmácia Popular do doutor Rodrigo Cambará, na saga de $O$ tempo e o vento.

O movimento agora era tão grande, que [Rodrigo] tivera de admitir mais dois empregados. Esse progresso se devia em grande parte às operações do Dr. Carlo Carbone. Felicitava-se de ter tido a ideia de trazer aquele italiano para Santa Fé. O diabo do gringo tinha mãos de mago: era indubitavelmente o maior operador que já aparecera no Rio Grande do Sul. Outra grande ideia fora a de construir no quintal da farmácia aqueles pavilhões de madeira com os quartos onde ficavam os doentes após as operações. Era uma espécie de paródia de sua tão sonhada casa de saúde... (Veríssimo, 1985, p.483).

Tempos depois, em 1926, o romancista gaúcho se tornaria sócio de uma farmácia, a Farmácia Central, de Érico Veríssimo \& Cia., embora nenhum talento tivesse para lidar com "o mundo dos xaropes, emplastros, pílulas e pomadas..."

Se a Farmácia Brasileira de meu pai fora das mais estranhas de que tenho notícia, a nossa não lhe ficava muito atrás. Não me seria possível registrar com minúcias os dramas, comédia e farsas de que nossa botica foi teatro - e teatro é a palavra exata. E ainda hoje, recordando aqueles dias, nossos erros, leviandades e falsas esperanças, não posso explicar como uma casa de comércio tão mal administrada como aquela pôde durar quase quatro anos (Veríssimo, 1978, p.200).

Como nos mostra o escritor gaúcho, a farmácia era em si um mundo de vivências e convivências e uma fonte riquíssima de elementos inspiradores para personagens, situações e ambientações.

O baiano Jorge Amado estudou direito, mas nem por isso deixou de descrever muito apropriadamente a figura do farmacêutico. Quem não se lembra do doutor Teodoro Madureira, 
proprietário da Farmácia Científica e segundo marido de dona Flor? Para traçar o perfil do sistemático, esperto e meticuloso boticário, certamente Amado buscou inspiração em algum profissional da área, visto que seus personagens eram sempre calcados em figuras que conhecia e observava em suas andanças. No romance, o doutor Teodoro era o profissional de reputação ilibada, correto e orgulhoso de frequentar a "gente de bem" na sociedade soteropolitana. Como se não bastasse toda sua competência da manipulação de elixires e xaropes, o farmacêutico ainda tocava fagote numa orquestra de amadores e conquistou o coração da cozinheira mais afamada da Bahia.

Doutor Teodoro surgiu na hora exata, na precisão de seu cronômetro suíço, numa lordeza que só vendo, flor à botoeira, um figurão esplêndido, a estremecer todas as comadres. Recebido com certa cerimônia por tia Lita, após cumprimentar todos os presentes, dirigiu-se ao lugar que, segundo rígido protocolo, lhe designaram: no sofá ao lado de dona Flor... O farmacêutico percorreu com os olhos a sala cheia, dona Norma sorriu a animá-lo. Então, pondo-se novamente de pé e dirigindo-se à dona Flor e aos tios, disse como ficaria feliz 'se ela quisesse lhe fazer a mercê de aceitá-lo como noivo, futuro esposo em breve prazo, dispondo-se a ser sua companheira na estrada da vida, estrada pedregosa, feita de obstáculos e tropeços, a transformar-se no entanto em paraíso se ele contasse com seu apoio e bálsamo...' (Amado, 1989, p.523).

O escritor e jornalista mineiro Manoel Lobato, nascido na pequena Assaraí, distrito de Pocrane, na Zona da Mata mineira, estudou farmácia no Rio de Janeiro, onde colou grau em 1949. Mais tarde se formou também em direito e trabalhou como jornalista para pagar os estudos, mas fez da atividade farmacêutica o sustento seu e de sua família. Menino pobre, órfão de pai muito cedo, foi criado vendo a mãe - uma farmacêutica prática - comandar o pequeno estabelecimento deixado pelo finado marido. Autor de inúmeros romances, contos e novelas, com obras traduzidas no exterior, narrou fragmentos biográficos no livro Cartas na mesa: memórias e manteve a Farmácia Lobato num bairro da capital mineira durante décadas (Lobato, 2002).

Outro talento que alternou as lides do comércio de remédios com a criação literária foi Antonio Avelino Fóscolo (1864-1944). E aqui vale a pena nos deter um pouco mais em sua curiosa trajetória de vida. Dotado de rara inteligência e de personalidade criativa, atuou em várias frentes: foi ator e autor de teatro, jornalista, escritor, militante da causa anarquista e, ao que consta, excelente farmacêutico prático. Chegou a criar fórmulas eficientes, uma delas destinada aos animais e chamada "O cevador", que era vendida como pão quente na farmácia, trazendo polpudos lucros ao criador da fórmula. É inexplicável como uma vida tão dinâmica e atuante tenha ficado tanto tempo no ostracismo. A academia o "descobriu" e vários trabalhos ${ }^{3}$ foram escritos sobre Fóscolo, seja como escritor, seja como líder anarquista.

Nascido em Sabará, Minas Gerais, viveu grande parte de sua vida em Taboleiro Grande (antiga denominação da cidade de Paraopeba), por conta do casamento com a filha de um farmacêutico. Tomou gosto pela profissão, aprendeu na prática e ajudou o sogro. Mais tarde tornou-se proprietário do estabelecimento e diversificou suas atividades, publicando um jornal e escrevendo peças e romances. A pequena cidade era próxima da tecelagem Fábrica do Cedro, propriedade da rica família Mascarenhas. Pois foi com os operários dessa fábrica que Fóscolo conviveu e serviu de líder para suas demandas contra os abusos perpetrados 
pelos proprietários da tecelagem, socorrendo aqueles que precisavam de medicamentos e não tinham como pagar. Devido à personalidade gregária e fascinante de Fóscolo, sua farmácia se tornou um local de grandes debates, políticos e literários. Como observa a historiadora Regina Horta Duarte (1991, p.40):

Numa sociedade tão modesta como aquela, pode-se avaliar a importância assumida pelo farmacêutico, superada apenas pelo padre, o prefeito e o delegado. Assim como a igreja, o prédio da prefeitura e a praça, a farmácia era um espaço-chave na vida daquelas pessoas. E a de Fóscolo ia muito bem. Com ela não dissociava nunca as atividades diversas que exercia: sua localização era na mesma casa que lhe servia de residência, laboratório para a fabricação de remédios, tipografia para a impressão de jornais... A farmácia não é visitada dessa forma, apenas por motivo de doença... era um lugar onde as pessoas se encontravam e várias questões, sérias ou insignificantes, eram discutidas.

Como farmacêutico, se interessava em estar sempre atualizado; por isso, esteve na Alemanha fazendo cursos. Fóscolo era simpatizante do anarquismo e é considerado um escritor naturalista, com forte influência de Émile Zola, Piotr Krpotkin (iniciador do anarcocomunismo), Jean Grave, além de estar sempre atualizado com as leituras dos autores da época, como Eça de Queiroz, Guerra Junqueiro e Tolstoi. Sua produção literária é permeada por preocupações humanistas e de justiça social e infelizmente pouco divulgada. Principais romances: Mulher, Caboclo e A capital.

Sua filha Adília foi uma das primeiras mulheres a se formar na Escola de Farmácia e teve como colega Carlos Drummond de Andrade, que lhe dedicou um poema escrito num caderno da farmacêutica:

\section{$\mathrm{Na}$ asa do vento}

Na asa do vento

Esta mulher não tem nome.

Esta mulher passou pelas ruas de Belo Horizonte

como o vento passa pelas árvores.

O vento passa pelas árvores...

Saí correndo e gritando atrás de sua sombra,

Saí correndo e gritando...

Nas pedras do calçamento,

Havia uma saudade infinita do seu passo,

e o seu passo foi mais breve que o vento.

Esta mulher tinha meu destino entre as mãos,

e sorrindo, e fugindo, perdeu-se no verde

da distância.

Carlos Drummond de Andrade, 1925 (citado em Malard, 1987, p.7).

O século XX mineiro foi, talvez, o período mais rico de sua história em produção literária, seja ela no romance, na poesia, na crônica, seja na memória, e, dentre tantos escritores 
oriundos de Minas Gerais, Lúcio Cardoso (1912-1968) é um dos grandes destaques. Seu romance, Crônica da casa assassinada, foi publicado pela primeira vez em 1959. Antes disso Cardoso já havia publicado outros romances, novelas, poesias, peças teatrais - várias delas encenadas em palcos cariocas e paulistas - e se dedicado também ao jornalismo, à pintura e à tradução. Como se não bastasse, o prolífico autor ainda escreveu para o cinema. O filme Porto das Caixas, de 1961, foi roteirizado (e dirigido) por Paulo César Saraceni a partir de uma história de Lúcio Cardoso e, ele mesmo, dirigiu também o filme A mulher de longe, além de roteirizar várias outras produções do cinema nacional.

Crônica da casa assassinada é considerado pelos críticos um dos romances fundamentais da literatura brasileira do século XX. Nele, Cardoso reservou para o farmacêutico da fictícia cidade de Vila Velha um papel de destaque na trama. Grosso modo, o tema do livro gira em torno das mazelas de uma família tradicional que vai, aos poucos, entrando numa espiral de decadência e promiscuidade, e no processo são revelados dilemas de cada um dos seus membros. O farmacêutico Aurélio também se envolve na vida dos Meneses por meio de troca de favores não muito éticos.

Procurei me informar do que se tratava, enquanto depositava a valise e retirava a capa que escorria. Disse-me o sr. Valdo que Dona Nina, logo após o jantar, sentara-se ao piano, sendo acometida de um mal súbito... Como habitualmente não gozasse de boa saúde, ele achara melhor mandar chamar alguém, pois nada entendia de medicina. $\mathrm{Na}$ ausência do doutor, a escolha recaíra sobre mim: não havia na cidade ninguém mais credenciado. E acrescentou que eu desculpasse o incômodo, mas que ele não seria avaro na recompensa (Cardoso, 2009, p.130).

Ainda sobre os mineiros não se poderia omitir Pedro Nava. Não, ele não era farmacêutico, e sim médico formado pela Faculdade de Medicina de Belo Horizonte, colega de sala do diamantinense Juscelino Kubitschek. Mas Nava aparece aqui como filho e neto de farmacêuticos (seu pai formou-se primeiro em Farmácia e depois em Medicina) e seus ancestrais cearenses possuíam estabelecimentos farmacêuticos em Fortaleza. E só por conviver estreitamente com Carlos Drummond de Andrade na mesma época em que os dois faziam seus cursos, já o gabarita para entrar na curiosa ligação entre a farmácia e a literatura.

O criador do Sítio do Picapau Amarelo, o paulista Monteiro Lobato (1882-1948) escreveu e idealizou, junto ao escritor paulista Léo Vaz (1890-1973), o primeiro número do Almanaque do Biotônico Fontoura, em 1920. Amigo de Cândido Fontoura Silveira (1885-1978) - farmacêutico e empresário do ramo de medicamentos -, fez de seu personagem, o Jeca Tatu, o maior estimulador das vendas dos medicamentos Biotônico Fontoura e o Ankilostomina Fontoura. O Jeca Tatu, uma controvertida caricatura do homem do campo brasileiro criada por Lobato, se investiria de tamanha força simbólica que, durante décadas, seria o elemento inspirador de músicas, filmes e histórias em quadrinhos.

Milhões de exemplares dessas publicações foram editados e distribuídos por todo o país. Formato ágil, equilibrando seu caráter intrinsecamente comercial com o espírito e o conteúdo dos almanaques tradicionais, levou não só às populações urbanas, mas a pequenas comunidades rurais, uma possibilidade de informação e entretenimento. Para muitos, em determinadas circunstâncias e frente à carência material e cultural do meio, o almanaque representou o livro e a revistinha infantil; em outras ocasiões, assumindo 
caráter e função particularmente inusitados, fez a vez da própria cartilha, auxiliando adultos e crianças no aprendizado da leitura (Gomes, 2006, p.2).

Esses almanaques financiados pelos laboratórios e pelas farmácias eram distribuídos por todo o Brasil. Foram lidos avidamente por gerações de brasileiros e tiveram escritores conceituados como colaboradores eventuais.

O escritor e político paulistano Menotti del Picchia (1892-1988) escreveu para o Almanaque Rodhia de 1936, e o dublê de poeta e publicitário pernambucano Manuel Bastos Tigre (1882-1957) colaborou em vários almanaques similares, criando para a Bayer o slogan "Se é Bayer, é bom". Este último foi assíduo colaborador da revista O Farmacêutico Brasileiro, patrocinada pela multinacional alemã Bayer. Como observou Mario Gomes (2006) em seu trabalho sobre a propaganda de medicamentos, vários escritores de renome colaboraram nos almanaques, mas, seja por pudor, seja por constrangimento, preferiram a "discrição do anonimato", por se tratar de publicações estritamente comerciais.

Até mesmo na literatura contemporânea o farmacêutico ainda é uma figura recorrente. O romance Sagrada família foi recentemente publicado pelo jornalista e escritor Zuenir Ventura (2012), que se inspirou nas lembranças da sua infância, passada no interior do Rio de Janeiro, para construir a história de uma típica família de classe média nos anos 40. O livro já começa dentro da farmácia do senhor Canuto, aonde a tia do narrador ia sempre tomar injeção, numa frequência para lá de suspeita... "A farmácia era para mim um mundo inebriante de cores, imagens e, sobretudo, aromas. Às vezes tenho a impressão de que toda a memória daquele tempo foi feita de fragrâncias, fixou-se em mim através do nariz - olfativa, mais que visual" (p.11).

Se voltarmos ao século XIX, notaremos que na literatura brasileira havia uma recorrência desses elementos ligados ao universo das farmácias e boticas. Em 1872, o visconde de Taunay (1843-1899) publicou Inocência, seu romance mais conhecido, ao lado do anterior $A$ retirada da Laguna (de 1869). Nele, o autor descreve as desventuras da jovem Inocência que, prometida em casamento ao rude Pereira pelo pai Manecão, acaba por se apaixonar por Cirino, um exestudante da Escola de Farmácia de Ouro Preto. Cirino anda pelos sertões - o romance tem como cenário o extremo leste do Mato Grosso do Sul, quase divisa com Minas - a curar os doentes com sua caixa de botica e seu ensebado Chernoviz, fazendo-se passar por médico. Ele pede pouso na fazenda do pai de Inocência, e os dois acabam se apaixonando e vivendo os dramas dos amores proibidos. O romance ainda serviu de roteiro para o filme homônimo de Walter Lima Jr. lançado em 1983.

Machado de Assis (1839-1908) também não deixou de lado o farmacêutico e numa crônica saborosa comenta um congresso que iria reunir farmacêuticos no Rio de Janeiro em 1877 e o medo que isso lhe suscitava por supor que poderia ser informado sobre quais os verdadeiros componentes dos remédios, preferindo tomá-los sem conhecer sua composição. Não teria o estímulo das propagandas de medicamentos e farmácias que ocupavam várias páginas dos jornais cariocas auxiliado na composição do personagem Brás Cubas? Teria algum farmacêutico inspirado o Bruxo do Cosme Velho para imaginar e criar o ambicioso projeto do emplastro idealizado pelo memorialista post mortem e batizado imodestamente como Emplastro Brás Cubas? 
A natureza, interessada na conservação da espécie humana, inspira a composição dos remédios, conforme a graduação patológica dos tempos. Já alguém disse, com grande sagacidade, que não há doenças, mas doentes. Isto que se diz dos indivíduos, cabe igualmente aos tempos, e a moléstia de um não é exatamente a de outro. Há modificações lentas, sucessivas, por modo que, ao cabo de um século, já a droga que a curou não cura; é preciso outra. Não me digam que, se isto é assim, a observação basta para dar a sucessão dos remédios. Em primeiro lugar, não é a observação que produz todas as modificações terapêuticas; muitas destas são de pura sugestão. Em segundo lugar, a observação, em substância, não é mais que uma sugestão refletida da natureza (Assis, 19 nov. 1893).

Um dos grandes ativistas da abolição, orador brilhante, segundo testemunhos, José do Patrocínio (1853-1905) se formou em farmácia; no entanto, sua condição social e financeira não permitiu sua dedicação ao ofício de farmacêutico. A pesquisadora e historiadora Verônica Velloso (2007, p.109) explica por quê.

Além daquela hierarquia dos saberes, importava a posição social ocupada pelo sujeito que os praticava. A ocupação de farmacêutico por si só não garantiria um lugar ao sol, dependia muitas vezes dos contatos ou apadrinhamentos a começar pela titulação pelos meios oficiais e depois, colocação... Vale citar aqui o caso de José do Patrocínio que se titulara farmacêutico pela Faculdade de Medicina do Rio de Janeiro, em 1874. Natural da cidade de Campos, negro e filho de padre, veio para a capital do império sem recurso algum, conseguindo ingressar como aprendiz na farmácia do Hospital da santa Casa da Misericórdia e depois no curso farmacêutico. Isso conseguiria graças à intervenção do seu conterrâneo o Conselheiro Albino Rodrigues de Alvarenga. Mas ao diplomar-se e não tendo recursos financeiros para montar uma farmácia, acabou enveredando pelo jornalismo.

No jornalismo, Patrocínio se destacou pela intensa luta a favor da libertação dos escravos e da implantação da República no Brasil. Trabalhou durante dez anos no jornal Gazeta de Notícias, no qual possuía a coluna Semana Política, que assinava com o pseudônimo de Proudhomme ${ }^{4}$ e, em 1887, fundou seu próprio jornal, intitulado A Cidade do Rio, veículo de grande importância na propaganda abolicionista. Seus artigos semanais na Gazeta se configuram como fonte histórica de grande valor, uma vez que seus comentários sobre a política coetânea revelam um analista lúcido e atento às nuanças e artimanhas da engenharia política na esfera do governo imperial. A Biblioteca Nacional disponibilizou recentemente a digitalização dos periódicos do século XIX, sendo possível aos interessados apreciar os artigos e comentários daquele que foi um dos próceres do movimento abolicionista. Uma pequena amostra de sua verve:

A herdeira do trono há de causar-lhe [ao imperador] tristeza; porque mostrar-se-á mais propensa a respeitar o Syllabus do que a Constituição: voz terá a melopeia das ladainhas à Virgem da Conceição, o espírito revelará o cansaço das longas Salve Rainhas e Credos. O seu esposo, sr. conde d'Eu, lhe aparecerá com sua alma de industrial, indiferente ao juízo público, obtendo de sua esposa que assine para seus mordomos de que ele mais tarde pede a transferência para si (Patrocínio, 1880, p.1). 
Sobre sua obra Bilac comentou: "Se fosse possível reunir todos os artigos, todos os discursos, com que Patrocínio atacou a escravidão e seus defensores, o livro em que ficassem compendiados esses libelos seria o mais belo poema da Justiça" (Carvalho, 1999, p.423).

Muitos outros optaram por personagens farmacêuticos, mas seria impraticável listar todos que usaram da figura desse profissional. Como exposto, um grande número de autores se valeu da figura do farmacêutico para compor o elenco de personagens de seus romances, contos ou novelas, corroborando a força simbólica de que o especialista da farmácia era revestido até algumas décadas atrás. A literatura ajudou, portanto, no resgate do papel do farmacêutico como sujeito histórico e agente dos processos de sociabilidade ocorridos nas pequenas e médias cidades brasileiras durante parte do século XIX e metade do XX.

\section{Alguns exemplos na literatura estrangeira}

Molière (1622-1673) fez uso constante de médicos e boticários em suas peças teatrais. Em pelo menos cinco delas os profissionais da saúde foram contemplados: L'amour médecin; Le médecin volant; Monsieur de Porceaugnac; Le médecin malgré lui; e, a mais conhecida entre nós, $O$ doente imaginário (Le malade imaginaire), última peça escrita por Molière, encenada pela primeira vez poucos dias antes de sua morte. Argan, o personagem rico e hipocondríaco, quer que sua filha Angélique se case com o filho do doutor Diafoirus para receber tratamentos de graça. Argan vive rodeado pelo médico e pelo boticário, monsieur Fleurant, que se aproveitam da sua mania de doenças para o explorar (Molière, 2008).

Existem muitos outros autores que mantiveram em alguma fase de sua vida forte ligação com a farmácia. O norueguês Henrik Ibsen (1828-1906) passou cinco anos de sua juventude como farmacêutico prático, antes de se tornar o maior expoente da dramaturgia de seu país. Chegou mesmo a pensar seriamente em se tornar médico depois de sua experiência no mundo das manipulações. Nesse caso também, perdeu a farmácia, mas ganhou o teatro, cujo autor legou à dramaturgia universal peças até hoje constantemente encenadas como Casa de bonecas, Peer Gynt, Um inimigo do povo, Hedda Glaber e muitas outras.

Do outro lado do mundo, na Rússia, na segunda metade do século XIX, Anton Tchekov (1860-1904), médico de formação, mas um excelente e prolífico escritor e dramaturgo, também usou a farmácia como elemento para um de seus contos. Em "A farmacêutica", Tchekov conta uma noite na vida de dois oficiais que resolvem conhecer a mulher do farmacêutico, famosa por sua beleza, durante uma noite fria, e a frustração de ambos quando seu plano é abortado pela acaso (Tchekov, s.d., p.41).

São inúmeros os casos de poetas e escritores interatuando com as ciências e cientistas intercambiando com a literatura e a poesia. Johann Wolfgang Von Goethe (1749-1832) é o caso exemplar de escritor e poeta que não só se interessava por temas científicos variados, mas fazia pesquisas científicas, mostrando que, além de uma personalidade multidisciplinar, Goethe foi um homem que representou seu tempo; tempo em que as ciências iniciavam um "distanciamento da metafísica e da teologia", privilegiando a razão. Em um artigo, Izabela Kestler (2006) revela que, em sua época de estudante de direito, o escritor alemão assistia constantemente aulas de química e anatomia. Essa capacidade de rejeitar a fragmentação do conhecimento em áreas estanques demonstra muito da genialidade de Goethe. Sem estar 
diretamente vinculada ao mundo da farmácia, a preocupação de Goethe com temas ligados à ciência faz dele um elemento a mais para fundamentar nosso texto.

Por fim, algumas palavras sobre o autor de Cem anos de solidão, livro que já vendeu cerca de trinta milhões de exemplares com traduções em mais de trinta idiomas. O escritor colombiano Gabriel García Márquez (2002) conta em suas memórias que não teve alternativa a não ser assumir a farmácia do pai. Natural de Aracataca, Márquez assistiu a sua mãe ser abandonada pelo marido com 11 filhos para criar e se viu empurrado para trás do balcão a vender fórmulas homeopáticas. Não teria sido a farmácia paterna inspiração para o laboratório de alquimia com que o cigano Melquíades presenteara o imaginoso José Arcádio Buendia no romance Cem anos de solidão? "Laboratório rudimentar - não se falando na profusão de caçarolas, funis, retortas, filtros e coadores - estava composto de uma tubulação primitiva; um provete de cristal, de pescoço comprido e estreito, imitação do ovo filosófico; e um alambique construído pelos próprios ciganos..." (García Márquez, s.d., p.12).

\section{O poeta e o namoro efêmero com a farmácia}

No Brasil, Affonso Romano de Sant'Anna (2006, p.217) também concorda com a visão goethiana: "Há, portanto, um determinado ponto em que a física e a metafísica se articulam como irmãs gêmeas, da mesma maneira que a poesia e a ciência", declarou o poeta mineiro numa entrevista.

Sant'Anna é autor também de um livro sobre a poesia de Carlos Drummond de Andrade, o que nos faz voltar ao fato que motivou o presente texto: Drummond e a farmácia. Pois bem, falemos um pouco dessa ligação do poeta itabirano com a Faculdade de Farmácia. Nas memórias de Pedro Nava fica evidente que Drummond nunca levou muito a sério o curso de farmacêutico, tamanho o número de episódios em que o memorialista conta os encontros e as conversas intermináveis dos companheiros reunidos no mítico Bar do Ponto ou no Café e Confeitaria Estrela, formando, junto com Aníbal Machado, Milton Campos e outros amigos, o Grupo do Estrela. Esses moços tiveram ativa participação na vida literária e no movimento modernista vivido na capital mineira e se projetariam mais tarde como escritores, poetas e até um governador (mas com o dom da escrita), no caso, Milton Campos.

Quando finalmente o curso de Farmácia chegou ao fim, Drummond foi escolhido na última hora como orador dos formandos - o orador inicialmente convidado adoecera subitamente - e iniciou seu discurso com a humildade que sempre lhe acompanhou, mas como Fernando Pessoa já advertira poeticamente:

O poeta é um fingidor.

Finge tão completamente

Que chega a fingir que é dor

A dor que deveras sente.

O nosso poeta também fingiu, certamente por elegância, outra virtude que sempre o caracterizou. "Considero a eloquência um simples substantivo, entre os milhares deles, masculinos ou femininos, que enxameiam o dicionário, sem nenhuma significação particular 
para mim, que me proponho ser um homem de laboratório e não um homem de tribuna" (Pianetti, 1988, p.74). Nada mais improvável vê-lo no laboratório entre balanças e tubos de ensaio. Na verdade, Carlos Drummond de Andrade nunca nutriu uma especial vocação por fórmulas e mezinhas, como revela este poema de sua autoria:

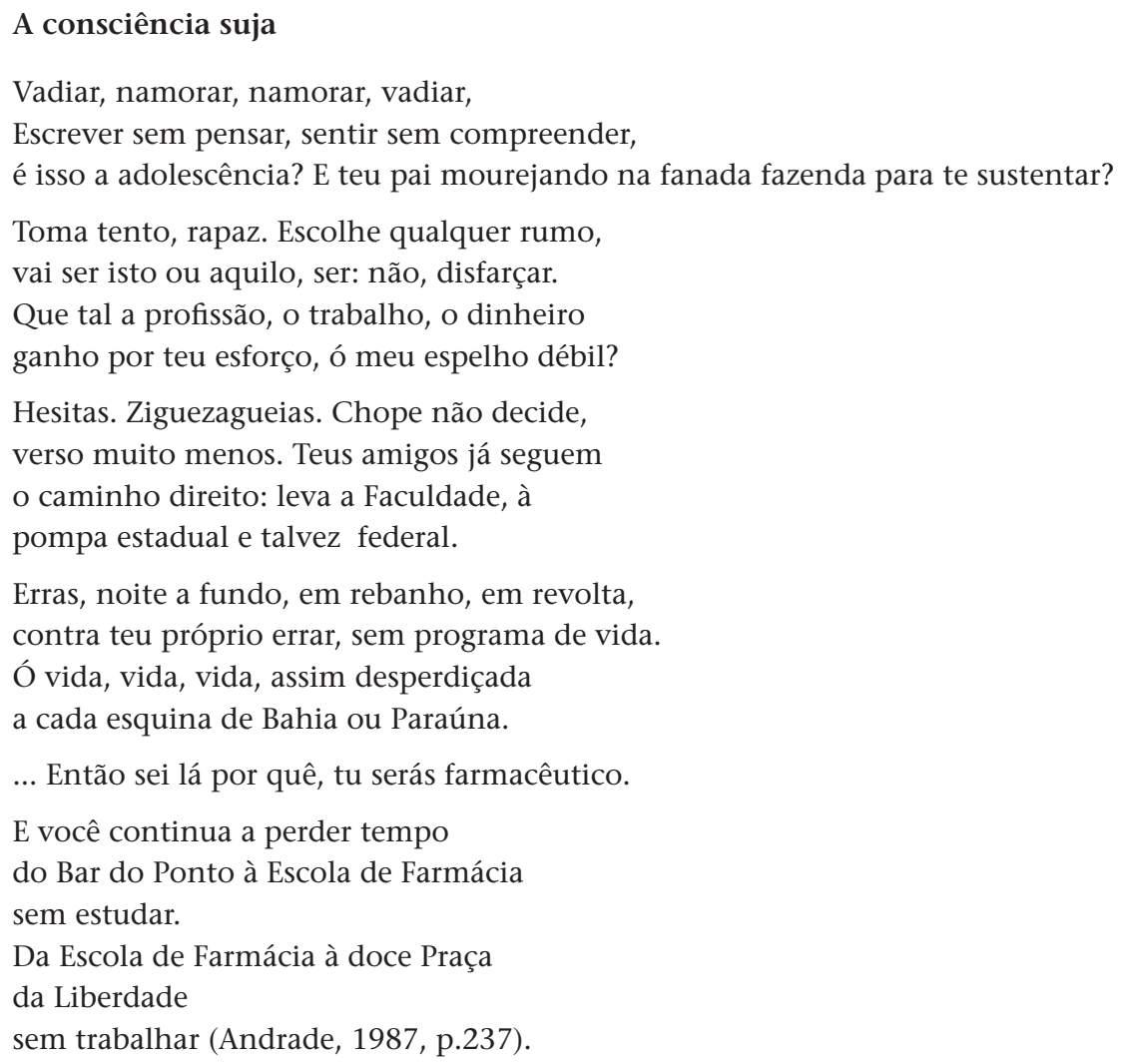

\section{Considerações finais}

Décadas depois de receber o diploma, Drummond foi convidado, certa vez, para honrar com sua presença uma solenidade na antiga escola. Declinou amável e coerentemente do convite. Afinal, ser farmacêutico nunca foi, definitivamente, sua vocação. Perdeu a profissão, mas ganhamos todos nós, brasileiros, farmacêuticos ou não, a deslumbrante obra poética do grande vate brasileiro, senão o maior.

Com sua verve característica, aguda e certeira, o médico e memorialista Pedro Nava aponta para uma reflexão final acerca dessa convergência entre a ciência, a história e a literatura: “Um doutorando em vésperas de colar grau de médico, em vez de só por seus livros de Medicina, interessava-se pelos de literatura. Respondo que Medicina antes de mais nada é conhecimento humano. E este está tanto nos livros de patologia e clínica como nos da obra de Proust, Flaubert, Balzac, Rabelais, dos poetas de hoje, de ontem, nos modernos como nos antigos" (Nava, 1985, p.390). Vale o mesmo para a farmácia e seu exercício. 


\section{AGRADECIMENTOS}

Ao professor doutor Gerson Antônio Pianetti, pela incansável e profícua supervisão.

À Coordenação de Aperfeiçoamento de Pessoal de Nível Superior pela Bolsa Programa Nacional de Pósdoutorado.

\section{NOTAS}

${ }^{1}$ No caso da Bayer travava-se também de uma disputa de mercado entre as empresas alemãs e as norteamericanas, que objetivavam eliminar as primeiras por causa da Segunda Guerra Mundial e, certamente, para ampliar suas vendas no promissor mercado brasileiro de medicamentos.

${ }^{2}$ O Farmacêutico Brasileiro: revista trimestral dedicada aos interesses da classe farmacêutica, fundada em 1932, circulou durante quase 30 anos. A ortografia foi atualizada para melhor compor a forma do texto.

${ }^{3}$ Sobre Avelino Fóscolo, ver Duarte (1991), Frieiro (1960), e Malard (1987).

${ }^{4} \mathrm{O}$ pseudônimo se referia, muito provavelmente, aos Conselhos de Proud'hommes (Conselhos de homens idôneos, numa tradução livre) criados por Napoleão para intermediar conflitos entre patrões e empregados. Essa hipótese é mais viável do que Patrocínio se valer do nome do poeta parnasiano francês Sully Prudhomme (1839-1907).

\section{REFERÊNCIAS}

AMADO, Jorge.

Dona Flor e seus dois maridos. In: Amado, Jorge. Jorge Amado: quatro mulheres, quatro romances. Rio de Janeiro: Nova Aguilar. 1989.

ANDRADE, Carlos Drummond de. Boitempo II. Rio de Janeiro: Record. 1987.

ASSIS, José Maria Machado de.

[Um dia destes...]. Disponível em: http://www. cronicas.uerj.br/home/cronicas/machado/rio_de_ janeiro/ano1893/19nov1893.html. Acesso em: $1 \overline{4}$ nov. 2012. 19 nov. 1893.

\section{BACZKO, Bronislaw.}

Imaginação social. In. Romano, Ruggiero (Org.). Enciclopédia Einaudi. v.5. Lisboa: Casa da Moeda. 1985.

CARDOSO, Lúcio.

Crônica da casa assassinada. Rio de Janeiro:

Civilização Brasileira. 2009.

CARVALHO, José Murilo de.

Pontos e bordados: escritos de história e política. Belo Horizonte: Ed. UFMG, 1999.

DUARTE, Regina Horta.

A imagem rebelde: a trajetória libertária de Avelino Fóscolo. Campinas: Pontes/Unicamp. 1991.

EDLER, Flávio Coelho.

Boticas \& pharmacias: uma história ilustrada da farmácia no Brasil. Rio de Janeiro: Casa da Palavra. 2006.

FLECK, Ludwik.

Gênese e desenvolvimento de um fato científico. Belo Horizonte: Fabrefactum. 2010.
FRIEIRO, Eduardo.

O romancista Avelino Fóscolo. Belo Horizonte: Imprensa Oficial. 1960.

GARCÍA MÁRQUEZ, Gabriel.

Vivir para contarla. Barcelona: Mandadori. 2002.

GARCÍA MÁRQUEZ, Gabriel.

Cem anos de solidão. Rio de Janeiro: Record. s.d.

GOMES, Mario Luiz.

Vendendo saúde! Revisitando os antigos

almanaques de farmácia. História, Ciências, Saúde

- Manguinhos, v.13, n.4, p.107-118. 2006.

KESTLER, Izabela Maria Furtado.

Johann Wolfgang Von Goethe: arte e natureza, poesia e ciência. História, Ciências, SaúdeManguinhos, v.13, supl., p.39-54. 2006.

LOBATO, Manoel.

Cartas na mesa: memórias. Belo Horizonte: Imprensa Oficial. 2002.

MALARD, Letícia.

Hoje tem espetáculo: Avelino Fóscolo e seu romance. Belo Horizonte: Ed. da Universidade Federal de Minas Gerais. 1987.

MOLIÈRE.

O doente imaginário. Belo Horizonte: Crisálida. 2008.

NAVA, Pedro.

Beira-mar: memória. v.4. Rio de Janeiro: Nova Fronteira. 1985.

O FARMACÊUTICO...

O Farmacêutico Brasileiro: revista trimestral 
dedicada aos interesses da classe farmacêutica, ano 13, n.51. set. 1938 .

O FARMACÊUTICO...

O Farmacêutico Brasileiro: revista trimestral dedicada aos interesses da classe farmacêutica, ano 10, n.37. mar. 1935.

PATROCÍNIO, José.

A semana política. Gazeta de notícias, ano 6, n.26, p.1. 26 jan. 1880.

PESAVENTO, Sandra Jathay.

História e literatura: uma velha nova história. Nuevo Mundo Mundos Nuevos, Débats. Disponível em: http://nuevomundo.revues.org/1560. Acesso em: 28 jan. 2013. 28 jan. 2006.

PESAVENTO, Sandra Jathay.

Com os olhos de Clio ou a literatura sob o olhar da história a partir do conto O alienista, de Machado de Assis. Revista Brasileira de História, v.16, n.31, p.108-118. 1996.

PIANETTI, Gerson Antonio.

O discurso do poeta: discurso de formatura de Carlos Drummond de Andrade. Revista de Farmácia e Bioquímica da Universidade Federal de Minas Gerais, v.9, p.73-77.1988.

PIRES, Aurélio.

O Norte, Belo Horizonte, 29 de junho de 1901. Fundo Aurélio Pires, cx. 1, doc. 06. (Arquivo Público Mineiro, Belo Horizonte). 29 jun. 1901.

POPPER, Karl.

A racionalidade das revoluções científicas. In: Harré, Rom. Problemas da revolução científica. Belo Horizonte: Itatiaia; São Paulo: Ed. da Universidade de São Paulo. 1976.
QUINTANEIRO, Tania.

O mercado farmacêutico brasileiro e o esforço de guerra norte-americano. Revista Estudos Históricos, v.1, n.29, p.141-164. 2002.

RODRIGUES, Henrique; NICOLAZZI, Fernando. Entrevista com François Hartog. História da historiografia, n.10, p.351-371. dez. 2012.

SANT'ANNA, Affonso Romano.

O lado poético das ciências: entrevista concedida a Carla Almeida.

História, Ciências e Saúde - Manguinhos, v.13, supl., p.213-222. 2006.

TCHEKOV, Anton.

Os mais brilhantes contos. Rio de Janeiro: Edições de Ouro. s.d.

VELLOSO, Verônica Pimenta.

Farmácia na Corte Imperial (1851-1887): práticas e saberes. Tese (Doutorado em História das Ciências e da Saúde) - Casa de Oswaldo Cruz/ Fiocruz, Rio de Janeiro. 2007.

VENTURA, Zuenir.

Sagrada família. Rio de Janeiro: Objetiva. 2012.

VERÍSSIMO, Érico.

O tempo e o vento. v.1. Porto Alegre: Globo. 1985.

VERÍSSIMO, Érico.

Solo de clarineta: memórias. Porto Alegre: Globo. 1978. 